\title{
Fetuin-A and YKL-40 serum levels and carotid intima-media thickness: Could they be good predictors for mild to moderate erectile dysfunction?
}

\author{
Original \\ Article \\ Naglaa F. Agamia ${ }^{1}$, Abeer S. El Hadidy', Amr M. El Abd ${ }^{3}$, Asmaa H.El-Atawy', Ali F. \\ El-Areny ${ }^{l}$ \\ Departments of ${ }^{\prime}$ Dermatology, Venerology and Andrology, ${ }^{2}$ Clinical and Chemical Pathology, \\ ${ }^{3}$ Radiodiagnosis, Faculty of Medicine, Alexandria University, Alexandria, Egypt.
}

\begin{abstract}
Background: Erectile dysfunction (ED) has been reported to occur as an early manifestation of atherosclerosis. Fetuin-A and YKL-40, (N-termianl amino acid: tyrosine (Y), lysine (K), leucine (L) and its molecular mass $40 \mathrm{kDs}$ ) which are glycoproteins secreted by many cells, significantly participate in formation of vascular tissue in healthy and diseased states.

Objective: This study aimed at assessment of serum fetuin-A and YKL-40 levels and the carotid intima-media thickness (CIMT) in patients with mild-moderate as well as moderate ED in comparison with control group.

Patients and Methods: A total of 90 patients with ED (grade mild-moderate) and 30 healthy participants who attend the outpatient clinic of the Andrology Department, Alexandria Main University Hospital, were included in the study. Enzymelinked immunosorbent assay was used for measuring both serum fetuin-A and serum YKL-40, and high-resolution B-mode ultrasound was used to measure the CIMT.

Results: Statistically significant low fetuin-A and high YKL-40 serum levels as well as a significant increase in CIMT were detected in patients with ED compared with controls. In addition, the ED severity showed a negative and positive correlation to fetuin-A and YKL-40 serum levels, respectively, but there was no correlation to CIMT.
\end{abstract}

Conclusion: fetuin-A and YKL-40 may be used as a predictor for cardiovascular risks in patients with mild to moderate ED..

Key Words: Carotid intima-media thickness, erectile dysfunction, fetuin-A, YKL-40.

Received: 25 March 2020, Accepted: 06 April 2020.

Corresponding Author: Naglaa F. Agamia, MD, Department of Dermatology, Venereology and Andrology, Faculty of Medicine, Alexandria University, Alexandria, Egypt, Tel.: +201008665048, E-mail: nogafathi03@yahoo.com.

ISSN: 2090-6048,

2019 Vol. 9, No.

\section{INTRODUCTION}

Erectile dysfunction (ED) is a frequently encountered disorder of male sexual function, manifested, at any age, as a failure to achieve and/or maintain an erection sufficient for a satisfactory sexual intercourse, which significantly negatively affectsthe patient's quality of life ${ }^{[1,2]}$.

Endothelial dysfunction has been detected in both cardiovascular diseases and ED. It is characterized by a reduced production ofnitric oxide (NO) which stimulatesvasodilation and enhances the vascular permeability tosome plasma proteins, like the lowdensity lipoproteins (LDL), as well. This defect leads to vasoconstriction, platelet aggregation, and leukocyte $\operatorname{adhesion}^{[3]}$.

Fetuin-A is a glycoproteinthat inhibits the process ofcalcification.The decrease and increase in its serum level may contributes to the process of inflammation andthen atherosclerosis ${ }^{[4]}$.
YKL-40, a $40-\mathrm{kD}$ chitin-binding glycoprotein, is an acute-phase protein produced in many cells, such as macrophage. It modulates tissue remodelingas well as acute and chronic inflammatory process ${ }^{[5-7]}$.

It was previously documented that YKL-40 has apathogenic role in early atherosclerotic process, leading to endothelial dysfunction and progression of the disease,which leads tocardiovascular clinical manifestations ${ }^{[5,6]}$. Serum YKL-40 has been found to be abnormally high in cardiovascular diseases like peripheral artery disease ${ }^{[8]}$, coronary artery disease ${ }^{[9]}$ and stroke ${ }^{[10]}$.

Carotid intima-media thickness (CIMT) is frequently used in epidemiological and interventional studies as animportant marker for early or subclinical atherosclerosis. Yet, data on the relationships between inflammatory biomarkers such as fetuin-A andYKL-40 and CIMT in patients with ED are insufficient ${ }^{[11]}$.

This study evaluated the serum YKL-40 and fetuin levels and CIMT in patients with ED (grade mild-moderate) 
to detect their relationship with the severity of the disease.

\section{PATIENTS AND METHODS}

A total of 90 male patients (group A) with either moderate or mild to moderate ED were recruited from outpatient clinic of Venereology and Andrology Department, Alexandria Main University Hospital, and 30age-matched healthy hospital staff members serving as controls (group B). All participants signed an informed written consent before joining the study.

Approval of the Ethics Committee of the University of Alexandria was obtained and the study committed to the ethical principles of the Declaration of Helsinki.

Patients with clinical history of coronary artery disease, dyslipidemias, diabetes mellitus (fasting glucose levels $>110 \mathrm{mg} / \mathrm{dl}$ ), kidney dysfunction, or anatomical disorder of penis; patients with major psychiatric or neurogenic disorders and patients receiving medications that affect sex hormones or other medications for ED or dyslipidemias (6 months before the study) were excluded.

Participants were clinically examined mainly to assess the testicular size. The International Index of Erectile Function-5 (IIEF-5) questionnaire, a validated, selfadministered, multidimensional tool, was used to define the severity of the $\mathrm{ED}^{[12]}$. Scores indicate the following: No ED if greater than or equal to 22, mild ED if 17-21, mild-moderate ED if $12-16$, moderate ED if $8-11$, and severe ED if 1-7 indicated.Patients were assigned to one of the two groups according to the severity of their $\operatorname{ED}[22$ patients (mild-moderate) and 38 patients (moderate)].

\section{Laboratory investigations}

Twelve-hour fasting blood samples were withdrawn between 8 a.m. and 10 a.m. to measure blood glucose, total cholesterol, LDL, high-density lipoprotein (HDL), and triglycerides using the autoanalyzer and applying the standardenzymaticmethods(Cobas311; RocheDiagnostics, Mannheim, Germany). Moreover,free testosterone was measured by the enzyme-linked immunosorbent assay method using a kit from Calbiotech(Austin, Texas,USA), whereas prolactin (PL)and total testosterone were measured by the chemiluminescent immunoassay (Architect Plus 1000 SR; Abbot Diagnostics, USA ).

Serum samples were stored at $-20^{\circ} \mathrm{C}$ until time of the assay analysis. YKL-40 and fetuin-A concentrations in EDTA plasma were measured in duplicates using a commercial enzyme-linked immunosorbent assay (Quidel, Santa Clara, California, USA). The cat number of human YKL-40 was EK0974, and its minimum detectable dose was less than $1.22 \mathrm{mg} / \mathrm{ml}$, whereas the cat number of fetuin-A was EK0757, and minimal detection limit was $0.04 \mathrm{ng} / \mathrm{ml}$.

\section{Radiological investigation}

\section{Measurement of carotid artery intima-media thickness}

CIMT is as a low-level echo gray band which does not project into the arterial lumen, represented, in duplex ultrasound system with $7.5 \mathrm{MHz}$ scanning frequency in the B-mode, pulsed Doppler mode, and color mode, as the distance between the leading edge of the first and second echogenic lines of the distantarterial walls during diastole $^{[13]}$. CIMT was evaluated, while patient is in the supine position, in plaque-free arterial segments of both the right and left common carotid arteries $(3 \mathrm{~cm}$ before the carotid bifurcation)andinternal carotid artery $(2 \mathrm{~cm}$ distally from the carotid bifurcation). The same radiologist performed all measurements to exclude bias.

Ahigh-resolution ultrasound (Siemens, ACUSON X 300 PE Ultrasound System, Siemens Medical Solutions, USA, Inc., California, USA), equipped with an VF13-5 wide bandwidth linear transducer, was used. The average value of both carotid arteries CIMTwas calculated ${ }^{[14,15]}$.

\section{Statistical analysis of the data ${ }^{[16]}$}

IBM SPSS software package version 20.0. (IBM Corp., Armonk, New York, USA) was used for data tabulation and analysis.Normal distribution of thequantitative data was determined by the Kolmogorov-Smirnov test. Quantitative data were expressed as a range (minimum and maximum), mean, $\mathrm{SD}$, and median. $\chi 2$ test was used to compare categorical variables and analyzed the significance between the different stages in different stages and groups. Quantitative data with a normal distribution were analyzed by the Student t-test. However, analysis of quantitative data with an abnormal distribution was done by the Mann-Whitney test as well as the Kruskal-Wallis test, and their associations were detected by the Spearman coefficient.Pairwise comparisons were done by the post-hoc (Dunn's multiple comparisons test), whereas comparison of data of more than two groups was done by the F-test (analysis of variance). Significance level was set at $5 \%$.

\section{RESULTS}

Demographic, clinical, and laboratoryfindings of all participants are depicted in Table 1, Insignificant differences were detectedbetween both groups regarding age, marital status, smoking behavior, blood pressure, testicular size, fasting blood glucose, lipid profile (serum cholesterol, TG, LDL, and HDL), serum testosterone (total and free), and serum PL (Table 1).

Our results showed significantly lower fetuin-A and significantly higher serum YKL-40in the studied group compared withcontrols $(P<0.001)$ (Table 1$)$. Moreover, 
serum fetuin-A level was significantly negatively correlated withserum YKL-40 level $(P=0.032)$.

Patients with moderate ED had a significantly higher serum YKL-40 and a significantly lower mean serum fetuin-A compared with those with mild-moderate ED (Table 2)

Moreover, IIEF-5 score was significantly positively correlated with fetuin-A andsignificantly negatively correlated with YKL-40 $(P<0.001)($ Fig. 1a and b).

The best cutoff value of serum fetuin-A and serum YKL-40 in the ROC curve in ED group was less than or equal to 1.911 and greater than $315.65 \mathrm{ng} / \mathrm{dl}$, respectively. The confidence interval of these predictive values was $0.621-0.890(P=0.007)$ in serum fetuin-A and $0.802-0.993(P<0.001)$ in serum YKL-40. The area under the curve of 0.751 in serum fetuin-A and 0.898 in serum YKL-40 (Fig.2a).

Serum fetuin-A and serum YKL-40 could predict moderate ED at the cutoff point ofless than or equal to $1.834 \mathrm{ng} / \mathrm{ml}$ and of greater than $456.45 \mathrm{ng} / \mathrm{ml}$, respectively.
The area under the curve was 0.863 for serum fetuin-A and 0.972 for serum YKL-40. The confidence interval of serum fetuin-A was 0.729-0.729 $(P<0.001)$ and serum YKL-40 was $0.923-1.0(P<0.001)$ (Fig.2b).

However, serum fetuin-A and YKL-40 could predict mild-moderate ED at a cutoff point ofless than or equal to $1.79 \mathrm{ng} / \mathrm{ml}$ and greater than $532.2 \mathrm{ng} / \mathrm{ml}$, respectively; the area under the curve was 0.823 in serum fetuin-A and 0.909 in serum YKL-40, and a confidence interval of $0.668-0.977(P<0.001)$ in serum fetuin-A and $0.747-0.983(P<0.001)$ in serum YKL-40 (Fig.2c).

The intima-media thickness of both common carotid arteries as well as the average value wassignificantly higher in ED cases than controls $(P<0.001)$ (Table 1). Yet, there was no significance correlation with fetuin-A and YKL40 serum levels. Similarly, the mean diameter of average common CIMT did not correlate with age of the patients, duration of the disease, atherogenic lipid profile, hormonal parameters, or with the IIEF-5 score $(P=0.758)$ (Fig. 3 and Table 3).

Table 1: Comparison between the two studied groups according to different parameters

\begin{tabular}{|c|c|c|c|c|}
\hline & Cases $(n=90)[n(\%)]$ & Control $(\mathrm{n}=30)[\mathrm{n}(\%)]$ & Test of significance & $P$ \\
\hline Age (years) & $45.6 \pm 3.2$ & $45.7 \pm 2.9$ & & 0.99 \\
\hline \multicolumn{5}{|l|}{ Marital state } \\
\hline Unmarried & $9(10.0)$ & $4(13.3)$ & & ${ }^{\mathrm{FE}} P=1.000$ \\
\hline Married & $81(90.0)$ & $26(86.7)$ & & \\
\hline \multicolumn{5}{|l|}{ Smoking } \\
\hline Non-smoker & $63(70.0)$ & $14(46.7)$ & & 0.128 \\
\hline Smoker & $27(30.0)$ & $16(53.3)$ & & \\
\hline \multicolumn{5}{|l|}{ Testis size $(\mathrm{mm})$} \\
\hline Right & $15.0 \pm 2.85$ & $15.53 \pm 2.75$ & $\mathrm{t}=0.598$ & 0.553 \\
\hline Left & $14.93 \pm 3.10$ & $16.53 \pm 2.29$ & $\mathrm{t}=1.769$ & 0.084 \\
\hline Average & $14.97 \pm 2.91$ & $16.03 \pm 1.88$ & $\mathrm{t}=1.288$ & 0.204 \\
\hline $\mathrm{FBG}(\mathrm{mg} / \mathrm{dl})$ & $88.0 \pm 8.15$ & $84.53 \pm 6.03$ & $\mathrm{t}=1.457$ & 0.152 \\
\hline \multicolumn{5}{|l|}{ Lipid profile } \\
\hline Serum cholesterol (mg/dl) & $145.40 \pm 22.98$ & $134.40 \pm 15.25$ & $t=1.674$ & 0.101 \\
\hline $\mathrm{TG}(\mathrm{mg} / \mathrm{dl})$ & $86.0 \pm 22.54$ & $75.47 \pm 16.47$ & $t=1.605$ & 0.116 \\
\hline $\operatorname{LDL}(\mathrm{mg} / \mathrm{dl})$ & $85.27 \pm 10.86$ & $79.0 \pm 12.94$ & $\mathrm{t}=1.711$ & 0.094 \\
\hline $\operatorname{HDL}(\mathrm{mg} / \mathrm{dl})$ & $42.10 \pm 3.95$ & $44.02 \pm 2.75$ & $t=1.684$ & 0.099 \\
\hline \multicolumn{5}{|l|}{ Hormonal parameters } \\
\hline Serum total testosterone $(\mathrm{ng} / \mathrm{dl})$ & $4.1(2.70-5.77)$ & $4.6(2.70-10.0)$ & $\mathrm{U}=162.0$ & 0.129 \\
\hline Serum free testosterone $(\mathrm{ng} / \mathrm{dl})$ & $92.01 \pm 10.99$ & $100.88 \pm 23.48$ & $\mathrm{t}=1.725$ & 0.092 \\
\hline Serum prolactin (ng/dl) & $8.0(3.90-15.0)$ & $7.1(5.03-9.06)$ & $\mathrm{U}=153.50$ & 0.085 \\
\hline
\end{tabular}




\begin{tabular}{lcccc}
\hline \multicolumn{2}{l}{ Intima-media thickness of common carotid artery $(\mathrm{mm})$} & & & \\
Left & $0.90 \pm 0.23$ & $0.51 \pm 0.10$ & $\mathrm{t}=7.919^{*}$ & $<0.001^{*}$ \\
Right & $0.86 \pm 0.21$ & $0.54 \pm 0.08$ & $\mathrm{t}=7.342^{*}$ & $<0.001^{*}$ \\
Average of two carotids & $0.88 \pm 0.20$ & $0.53 \pm 0.08$ & $\mathrm{t}=8.606^{*}$ & $<0.001^{*}$ \\
Serum fetuin-A (ng/ml) & $1.8(1.48 \pm 5.47)$ & $2.1(1.77 \pm 3.0)$ & $\mathrm{U}=2.721^{*}$ & $0.007^{*}$ \\
Serum YKL-40 (ng/ml) & $606.4(173.9 \pm 2005.6)$ & $263.3(145.6 \pm 649.7)$ & $\mathrm{U}=46.0^{*}$ & $<0.001^{*}$ \\
\hline
\end{tabular}

$x^{2}: x^{2}$ test for comparing between the two groups; FBG, fasting blood glucose; FEP: $P$ value for Fisher exact for $x^{2}$ test for comparing between the two groups; HDL, high-density lipoprotein;LDL, low-density lipoprotein; t, $P: \mathrm{t}$ and $P$ values for Student'st-test for comparing between the two groups; TG, triglycerides; U, P: U and P values for Mann-Whitney test for comparing between the two groups.

*Statistically significant at $P \leq 0.05$

Table 2: Relation between severity and different parameters in cases group

\begin{tabular}{|c|c|c|c|c|}
\hline \multicolumn{5}{|c|}{ Severity } \\
\hline & $\begin{array}{l}\text { Moderate ID } \\
(8-11)(\mathrm{n}=58)\end{array}$ & $\begin{array}{l}\text { Mild to moderate ID } \\
\quad(12-16)(n=32)\end{array}$ & $\mathrm{U}$ & $P$ \\
\hline \multicolumn{5}{|l|}{ Serum YKL-40 (ng/ml) } \\
\hline Minimum-maximum & $419.18-2005.58$ & $173.90-1189.82$ & $19.0^{*}$ & $<0.001 *$ \\
\hline Mean \pm SD & $988.50 \pm 514.90$ & $463.57 \pm 268.51$ & & \\
\hline Median & 768.61 & 374.20 & & \\
\hline \multicolumn{5}{|l|}{ Serum fetuin-A (ng/ml) } \\
\hline Minimum-maximum & $1.48-2.49$ & $1.67-5.47$ & 37.0 & $0.004^{*}$ \\
\hline Mean \pm SD & $1.78 \pm 0.27$ & $2.38 \pm 1.14$ & & \\
\hline Median & 1.73 & 1.91 & & \\
\hline
\end{tabular}

$\mathrm{t}, P: \mathrm{t}$ and $P$ values for Student'st-test for comparing between the two groups; $\mathrm{U}, P: \mathrm{U}$ and $P$ values for Mann-Whitney test for comparing between the two groups, ${ }^{*} P<0.05$
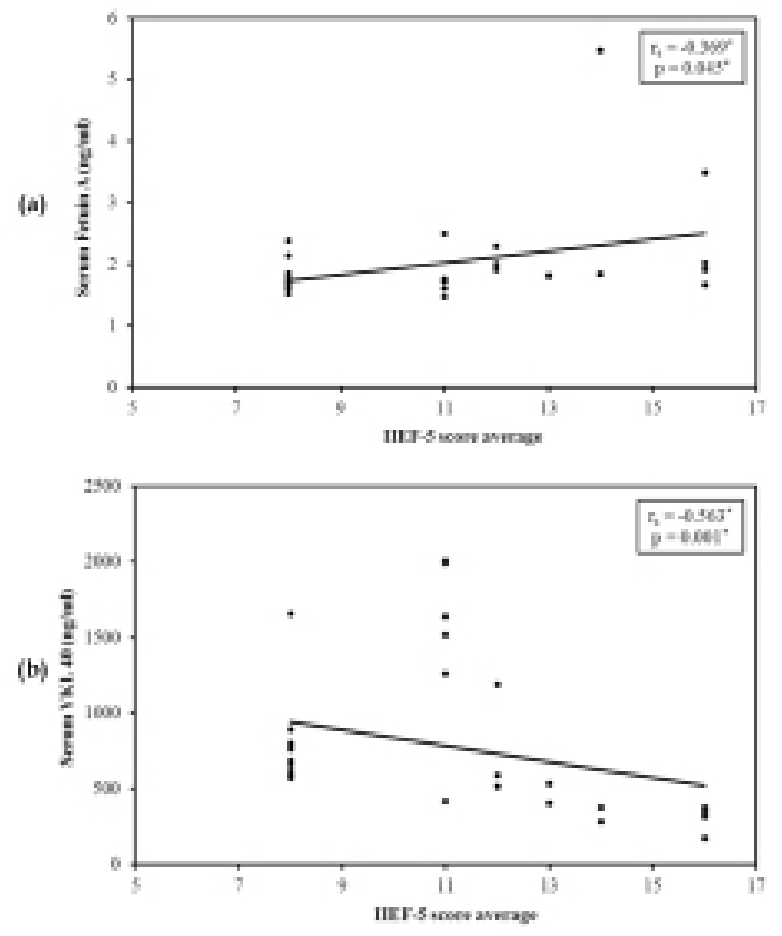

Fig. 1: (a) Correlation between serum fetuin-A (ng/ml) and IIEF-5 score average in cases group. (b) Correlation between serum YKL-40 (ng/ml) and IIEF-5 score average in cases group.IIEF-5, International Index of Erectile Function-5. 


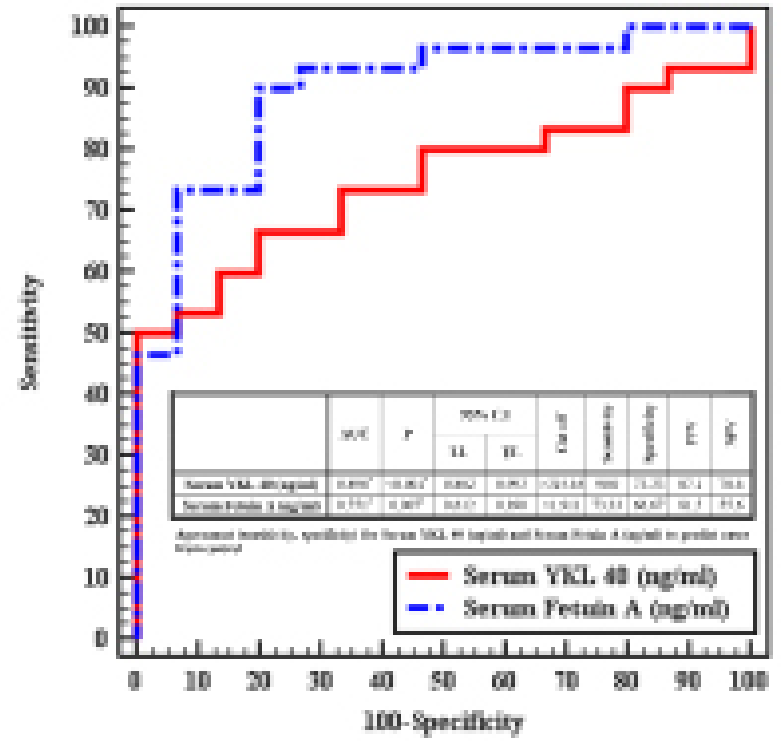

$2 \mathrm{a}$

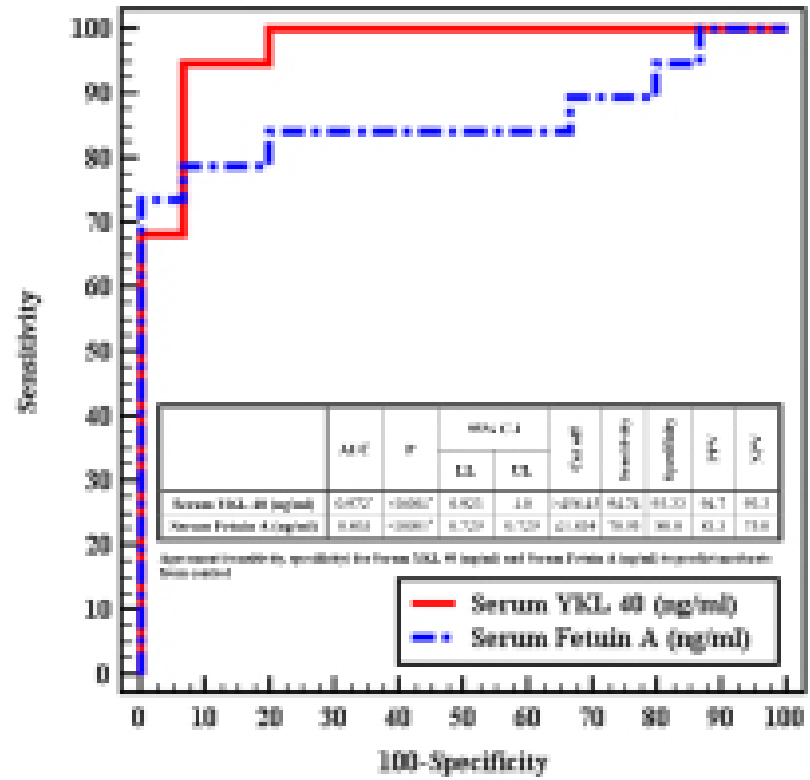

$2 b$

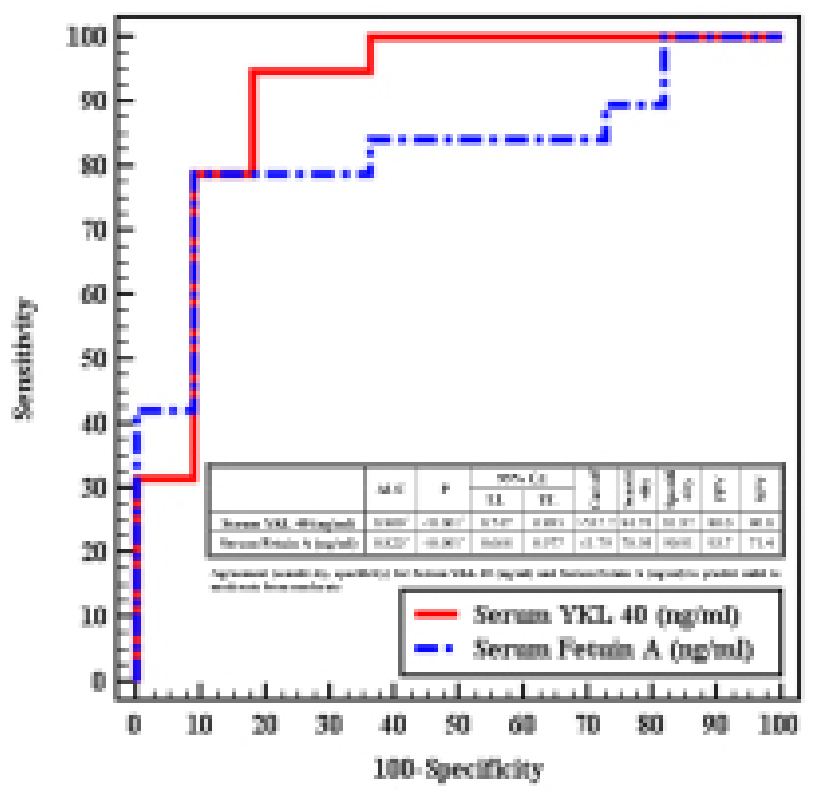

$2 \mathrm{c}$

Fig. 2: (a) ROC curve forserum YKL-40 (ng/ml) and serum fetuin-A (ng/ml) to predict cases from control and agreement (sensitivity and specificity) for serum YKL-40 (ng/ml) and serum fetuin-A (ng/ml) to predict cases from control. (b) ROC curve forserum YKL-40 (ng/ml) and serum fetuin-A ( $\mathrm{ng} / \mathrm{ml}$ ) to predict moderate from control and agreement (sensitivity and specificity) for serum YKL-40 (ng/ml) and serum fetuin-A (ng/ml) to predict moderate from control. (c) ROC curve forserum YKL-40 (ng/ml) and serum fetuin-A (ng/ml) to predict mild to moderate from moderate and agreement (sensitivity and specificity) for serum YKL-40 (ng/ml) and serum fetuin-A (ng/ml) to predict mild to moderate from moderate. ROC, receiver operating characteristic curve. 


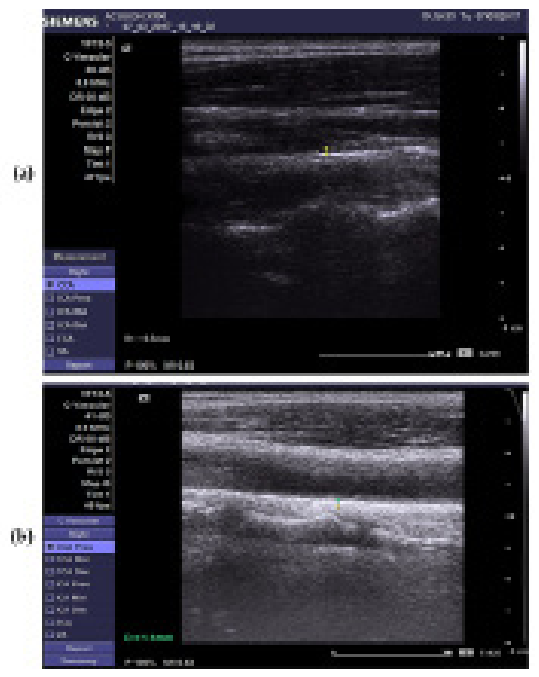

Fig. 3 (a) Carotid Doppler ultrasound of the CCA with normal CIMT (left common carotid artery intima-media thickness=0.5 m). (b) Carotid Doppler ultrasound of CCA showing intimal thickness of left and right CCA (left common carotid artery intima-media thickness=1.1 mm). CIMT, carotid intima-media thickness.

Table 3: Correlation between different parameters in patient group $(n=60)$

\begin{tabular}{|c|c|c|c|c|c|c|}
\hline & \multicolumn{2}{|c|}{ Serum fetuin-A (ng/ml) } & \multicolumn{2}{|c|}{ Serum YKL-40 (ng/ml) } & \multicolumn{2}{|c|}{$\begin{array}{l}\text { Intima-media thickness of } \\
\text { common carotid artery }(\mathrm{mm}) \\
\text { (average of two carotids) }\end{array}$} \\
\hline & $r_{s}$ & $P$ & $r_{s}$ & $P$ & $r_{s}$ & $P$ \\
\hline FBG (mg/dl) & -0.184 & 0.331 & 0.300 & 0.107 & 0.017 & 0.928 \\
\hline HbAlc (\%) & 0.195 & 0.303 & -0.069 & 0.717 & -0.229 & 0.224 \\
\hline \multicolumn{7}{|l|}{ Lipid profile } \\
\hline Serum cholesterol (mg/dl) & 0.105 & 0.580 & 0.071 & 0.709 & 0.188 & 0.319 \\
\hline $\mathrm{TG}(\mathrm{mg} / \mathrm{dl})$ & $-0.386^{*}$ & $0.035^{*}$ & 0.260 & 0.166 & 0.035 & 0.854 \\
\hline $\operatorname{LDL}(\mathrm{mg} / \mathrm{dl})$ & -0.136 & 0.473 & $0.524^{*}$ & $0.003 *$ & -0.185 & 0.328 \\
\hline HDL (mg/dl) & 0.019 & 0.919 & -0.234 & 0.214 & 0.338 & 0.067 \\
\hline \multicolumn{7}{|l|}{ Hormonal parameters } \\
\hline Serum total testosterone (ng/dl) & 0.106 & 0.577 & -0.080 & 0.674 & 0.0 & 0.998 \\
\hline Serum free testosterone $(\mathrm{ng} / \mathrm{dl})$ & 0.148 & 0.434 & 0.036 & 0.849 & -0.242 & 0.198 \\
\hline Serum prolactin $(\mathrm{ng} / \mathrm{dl})$ & 0.216 & 0.252 & -0.352 & 0.056 & 0.103 & 0.588 \\
\hline Age (years) & $-0.369^{*}$ & $0.045^{*}$ & $0.428^{*}$ & $0.018^{*}$ & 0.035 & 0.856 \\
\hline IIEF-5 score average & $0.462^{*}$ & $0.010^{*}$ & $-0.563^{*}$ & $0.001^{*}$ & -0.059 & 0.758 \\
\hline Duration of the disease (years) & 0.334 & 0.071 & -0.169 & 0.372 & -0.268 & 0.152 \\
\hline
\end{tabular}

FBG, fasting blood glucose; HDL, high-density lipoprotein; IIEF-5, International Index of Erectile Function-5; LDL, low-density lipoprotein; rs, Spearman coefficient; TG, triglycerides.

*Statistically significant at $P \leq 0.05$.

\section{DISCUSSION}

Sexual dysfunction of vascular origin is owing to atherosclerosis of the penile arteries. Therefore, sexual dysfunction is more frequently detected in patients at risk of cardiovascular diseases rather than in individuals free of such risk ${ }^{[17]}$.

Similar findings were reported by Karabakan et al. ${ }^{[17]}$ and Kandeel et al. ${ }^{[18]}$, where both studies showed insignificantly variable fasting blood glucose and lipid profile (cholesterol, TG, LDL, and HDL). This insignificance was intended to exclude other causes that may contribute to endothelial dysfunction (Table 1). Similarly, Karabakan et al. ${ }^{[17]}$ found an insignificant different between patients and controls regarding total testosterone and PL serum levels. However, Kandeel et $a l^{[18]}$ demonstrated significant elevation of testosterone serum level in patients compared with controls.

Atherosclerosis is a systemic process that affects the whole arterial system. The patient's risk-factor profile 
(which was excluded in patients) is not the only determinant of endothelial dysfunction. Endothelial function in all stages of the atherosclerotic process is additionally affected by subclinical low-grade inflammation. Carotid arteries can be easily visualized to evaluate the degree of atherosclerosis. CIMT reflects endothelial dysfunctions, thus the risk of CVD as well ${ }^{[19]}$. Our results agreed with Unal et al. ${ }^{[11]}$, who concluded in their study that ED correlated with subclinical endothelial dysfunction, assessed by measuring the CIMT, and ED scores correlated inversely with CIMT as well.

Regarding fetuin-A serum level, our results agree with Kandeel et al. ${ }^{[18]}$ who proved that fetuin-A serum level was found to be significantly lower in cases with severe ED than those with mild or moderate ED. In the same way, Karabakan et al. ${ }^{[17]}$ also reported that fetuin-A serum level significantly positively correlated with the IIEF- 5 score in patients with ED, and this was proved by the present study.

Although this study detected a positive significant correlation between serum fetuin-A and age of the patients (Table 3), Harrison et al. ${ }^{[20]}$ and Kandeel et al. ${ }^{[18]}$ failed to prove this significant correlation in their studies, which could be attributed to the small sample size.

Gulhan et al. $\left.{ }^{[21}\right]$ could not detect any association between serum fetuin-A and serum testosterone $(P=0.47)$, which was compatible with the present study.

Regarding the correlations to the atherogenic lipid profile, the present study proved that serum fetuin-A was only strongly associated with TG serum level (Table 3), and this was also documented by several other studies - to a variable degrees - such as Karabakan et al..$^{[17]}$ and Yin et al. ${ }^{[22]}$, which reported in their studies that fetuin-A was significantly positively correlated with triglyceride and LDL-C plasma levels and negatively correlated with HDL-C. Khalil et al. ${ }^{[23]}$ and Marechal et al. ${ }^{[2]}$ also concluded the same results in this their studies.

According to Schoppet et al. ${ }^{[25]}$, fetuin-A is a reliable biomarker for endothelial dysfunction in patients with ED and low fetuin-A level could be a participant in the pathogenesis of vascular calcification independent of smoking, hypertension, or renal failure.

Previous studies suggested that microvascular and macrovascular alterations are preceded by endothelial dysfunction, which may be used as an early diagnostic predictor of preclinical target organ damage in both highrisk individuals, in which vascular damage is already established, and low-risk individuals, who will benefit most by early interference ${ }^{[26]}$.

YKL-40 has been linked to the pathogenesis of early and late phases of atherosclerosis, as its level has been demonstrated to be abnormally high in cases with coronary artery disorders, and such elevation is significantly correlated with the severity of the cardiovascular insult $^{[27]}$. Similar to the finding of the present study,
Thomsen et al. ${ }^{[29]}$ reported an association between the elevated serum cholesterol and LDL and the elevated serum YKL-40 (Table 3).

Like the present study, Yamamori et al. ${ }^{[28]}$, Thomsen et al. ${ }^{[29]}$, and Sabry et al. ${ }^{[26]}$ reported a significant association between the serum YKL-40 and age. Aging is one of the main factors that predispose people to endothelial dysfunction. The mechanism of endothelial dysfunction during the aging process is accompanied by imbalance between an increase in the production of cyclooxygenasederived vasoconstrictor factors and reduction of the expression and activity of e NOS. However, endotheliumderived contracting factors, such as ROS production, ET-1, and cyclooxygenase-derived prostanoids, are increased $^{[30]}$

Furthermore, the contribution of YKL-40 in the vascular pathology suggests its involvement in the lowgrade inflammation which occurs before the onset of the endothelial dysfunction ${ }^{[5]}$. Similarly, Sabry et al. ${ }^{[26]}$ concluded a significant increase of this marker in early stages of ED patients.

Sabry et $a l^{[26]}$ showed in their study that the optimum cutoff value of YKL-40 concentration was $50 \mathrm{ng} / \mathrm{ml}$ for distinguishing arteriogenic patients with ED from healthy controls, with $85 \%$ sensitivity, $68 \%$ specificity, and $73 \%$ accuracy, whereas in our study, serum YKL-40 had sensitivity of $90.0 \%$ and specificity of $73.33 \%$ in all patients with ED.

According to the results reported by Kandeel et al. ${ }^{[18]}$, serum fetuin-A can predict patients with ED in general with high sensitivity, specificity, and accuracy, and patients with According to the results reported by Kandeel et al. ${ }^{[18]}$, serum fetuin-A can predict patients with ED in general with high sensitivity, specificity, and accuracy, and patients with mild ED, with $70 \%$ sensitivity, $70 \%$ specificity, and $70 \%$ accuracy at a cutoff value of greater than or equal to $194.3-266.3 \mathrm{ng} / \mathrm{ml}$. This was compatible with our results, where serum fetuin-A was $73.33 \%$ sensitive and $66.67 \%$ specific in all patients (moderate and mild to moderate ED) (Fig. 2a), whereas $78.95 \%$ sensitivity and $90.91 \%$ specificity in patients with mild to moderate ED alone at a cutoff point of less than or equal to $1.79 \mathrm{ng} / \mathrm{ml}$ (Fig. 2c)

\section{CONCLUSION}

This study proved that both YKL-40 fetuin-A could be highly sensitive and specific for predicting and diagnosing patients with mild and moderate ED. CIMT measurement by ultrasonography appears to be a useful, simple and noninvasive tool that detects subclinical atherosclerosis in patients with ED who seem to be otherwise healthy.

\section{CONFLICT OF INTEREST}

There are no conflicts of interest. 


\section{REFERENCES}

1. Lizza E.F., Rosen R.C. Definition and classification of erectile dysfunction: report of the Nomenclature Committee of the International Society of Impotence Research. Int J Impot Res 1999; 11:141-143.

2. Feldman H.A., Goldstein I., Hatzichristou D.G., Krane R.J., McKinlay J.B. Impotence and its medical and psychosocial correlates: results of the Massachusetts Male Aging Study. J Urol 1994; 151:54-61.

3. Kirby M., Jackson G., Simonsen U. Endothelial dysfunction links erectile dysfunction to heart disease. Int J Clin Pract 2005; 59:225-229.

4. Akalin N., Altiparmak M.R., Trabulus S., Ataman R., Ayan F., Yetik H., et al. Correlation of clinical effects with levels of fetuin-A, FGF-23 and intact parathyroid in peritoneal dialysis patients. Int $\mathrm{J}$ Biomed Adv Res 2015; 6:488-494.

5. Rathcke C.N., Vestergaard H. YKL-40, a new inflammatory marker with relation to insulin resistance and with a role in endothelial dysfunction and atherosclerosis. Inflamm Res 2006; 55:221-227.

6. Rathcke C.N., Vestergaard H. YKL-40-An emerging biomarker in cardiovascular disease and diabetes. Cardiovasc Diabetol 2009; 8:61.

7. Lee C.G., da Silva C.A., Cruz C.S., Ahangari F., Ma B., Kang M.J. Role of chitin and chitinase/chitinaselike proteins in inflammation, tissue remodeling, and injury. Ann Rev Physiol, 2011;73:479-501.

8. Batinic K., Höbaus C., Grujicic M., Steffan A., Jelic F., Lorant D., et al. YKL-40 is elevated in patients with peripheral arterial disease and diabetes or prediabetes. Atherosclerosis 2012; 222:557-563.

9. Xie F., Qian Q., Chen Z., Ma G., Feng Y. Chitinase 3-like 1 gene-329G/A polymorphism, plasma concentration and risk of coronary heart disease in a Chinese population. Gene 2012; 499:135-138.

10. Rathcke C. N., Thomsen S.B., Linneberg A. Variations of CHI3L1, levels of the encoded glycoprotein YKL-40 and prediction of fatal and non-fatal ischemic stroke. PLoS One 2012; 7:e43498.

11. Unal M., Aksoy D.Y., Aydın Y., Tanriover M.D., Berker D., Karakaya J., Guler S. Carotid artery intima-media thickness and erectile dysfunction in patients with metabolic syndrome. Med Sci Monit $2014 ; 29 ; 884-888$.
12. Rosen R. C., Cappelleri J.C., Smith. M.D., Lipsky. J., Pena. B.M. Development and evaluation of an abridged, 5-item version of the International Index of Erectile Function (IIEF-5) as a diagnostic tool for erectile dysfunction. Int $\mathrm{J}$ Impot Res 1999; 11:319-326.

13. Lim T.K., Lim E., Dwivedi G., Kooner J., Senior R. Normal value of carotid intima-media thickness - a surrogate marker of atherosclerosis: quantitative assessment by B-mode carotid ultrasound. J Am Soc Echocardiogr 2008; 21:112-116

14. Jarauta E., Mateo-Gallego R., Bea A., Burillo E., Calmarza P., Civeira F. Carotid intima-media thickness in subjects with no cardiovascular risk factors. Rev Esp Cardiol 2010; 63:97-102.

15. Lue T.F. Erectile dysfunction. N Engl J Med 2000; 342:1802-1813.

16. Kirkpatrick L.A., Feeney B.C. A Simple Guide to IBM SPSS Statistics for Version 20.0. Student ed. Belmont, CA: Wadsworth, Cengage Learning; 2013. 29:189-193.

17. Karabakan M., Bozkurt A., Gunay M., Aktas B.K., Hirik E., Aydın M., et al. Association between serum fetuin-A level and erectile function. Andrologia 2015; 48:787-792.

18. Kandeel W., El-Shaer W., Sebaey A., Abou-Taleb A.A., Fathy A., Elmohamady B., et al. Usefulness of serum fetuin-A level as a marker of erectile dysfunction. Int J Impot Res 2017; 29:189-193.

19. Lin E., Hwang W. Imaging assessment of cardiovascular risk in asymptomatic adults. Am J Roentgenol 2011; 197:W1046-W1051.

20. Harrison D., Griendling K.K., Landmesser U., Hornig B., Drexler H. Role of oxidative stress in atherosclerosis. Am J Cardiol 2003; 91:7A-11A.

21. Gulhan I., Bozkaya G., Oztekin D., Uyar I., Kebapcilar A.G., Pamuk B. Serum Fetuin-A levels in women with polycystic ovary syndrome. Arch Gynecol Obstet 2012; 286:1473-1476.

22. Yin L., Cai W.J., Zhu L.Y., Li J., Su X.H., Wang X.L., et al. Association of plasma Fetuin-A and clinical characteristics in patients with newonset type 2 diabetes mellitus. Int J Clin Exp Med 2015; 8:991-999.

23. Khalil H, Faizehalkuobaili I. Elevated fetuin - a 
level associated with an atherogenic lipid profile in type 2 diabetes. Int J Pharm Sci 2013; 4: 266-269.

24. Mare'chal C., Schlieper G., Nguyen P., Kruger T., Coche E., Robert A. et al. Serum fetuin-a levels are associated with vascular calcifications and predict cardiovascular events in renal transplant recipients. Clin J Am Soc Nephrol 2011; 6:974-985.

25. Schoppet M., Rauner M., Benner J., Chapurlat R., Hofbauer L.C., Szulc P. Serum fetuin-A levels and abdominal aortic calcification in healthy men- The STRAMBO study. Bone 2015; 79:196-202.

26. Sabry H. H., Hamed A. H., Sabry J.H., Abdel-Salama O.H. YKL-40: an emerging biomarker of endothelial dysfunction in arteriogenic erectile dysfunction. Hum Androl 2017; 7:98-104.

27. Kucur M., Isman F.K., Karadag B., Vural V.A.,
Tavsanoglu S. Serum YKL-40 levels in patients with coronary artery disease. Coron Artery Dis 2007; 18:391-396.

28. Yamamori H., Hashimoto R., Ohi K., Yasuda,Y., Fukumoto M., Kasahara E., et al. A promoter variant in the chitinase 3-like 1 gene is associated with serum YKL-40 level and personality trait. Neurosci Lett 2012; 513:204-208.

29. Thomsen S.B., Rathcke C.N., Skaaby T., Linneberg A., Vestergaard $\mathrm{H}$. The association between genetic variations of $\mathrm{CHI} 3 \mathrm{~L} 1$, levels of the encoded glycoprotein YKL-40 and the lipid profile in a Danish population. PLoS One 2012; 7:e47094.

30. Ungvari Z., Kaley G., de Cabo R., Sonntag W.E., Csiszar A. Mechanisms of vascular aging: new perspectives. J Gerontol A Biol Sci Med Sci 2010; 10:1028-1041. 